\title{
Occurrence of Organizational Crises: Cause and Effect Relationships in Process Technology
}

\author{
Prof. PhD Tzveta Zafirova \\ University of Economics - Varna, Varna, Bulgaria \\ tzveta_zafirova@ue-varna.bg
}

\begin{abstract}
The paper's objective is to investigate the reasons to organizational crises and the factors influencing these processes. System, process and holistic approaches are applied to the study. The reason-and-effect links have been clarified in the process of organizational crises. A critical analysis of the specialized literature and practice in the field has been made. The determination of all the elements, units and links in it will help in the process of its management. This research will assist the managers in taking the proper decisions for the future development of the organization and ignore the reasons for crisis situations.
\end{abstract}

Keywords: organizational crises, reasons, factors, system and process approaches

JEL Code: M100, G330; doi:10.36997/IJUSV-ESS/2019.8.1.64

\section{Въведение}

Организационните кризи са често срещано явление в последните години. Кризите могат да възникнат във всеки етап на развитие на организацията - както в периода на зараждане и развитие, така и при стабилизацията и разширението й, и накрая - в спада на жизнения й цикъл.

Mitroff и Anagnos (2001) посочват, че „кризата е събитие, което засяга или има потенциала да засегне цялата организация”. Практиката в областта на кризите доказва тази теза.

Всяка организация представлява система от взаимно-свързани елементи, като негативните промени в тях се отразяват на цялата система. Това потвърждава необходимостта от прилагане на системен подход в изследването на цялостния процес на организационните кризи от появата на първите симптоми, породени от различни причини, до последствията от нея. Не бива да се игнорира въздействието и на външната среда, тъй като много често именно промените в нея водят до негативните явления и процеси, създават изострени отношения вътре в организацията.

Целта на публикацията е изследване на причините, които водят до организационни кризи и факторите, които влияят на тези процеси и ролята им в причинно-следствената верига.

Идентифицират се причинно-следствената връзка и взаимозависимостите в процеса на кризите в организациите. Проучени са специализираната литература и практиката в областта, като е направен критичен анализ и оценка. При изследването, освен системен и процесен, е приложен и холистичен подход.

\section{1. Причинно-следствена верига на процеса на организационна криза}

В научната литература съществуват голям брой тълкувания на понятието организационна криза. В това изследване е прието, че „това е поява на драматични явления и процеси във външната и/или вътрешната среда на организацията, имащи пряко или непряко въздействие върху нея, когато използваните до този момент методи на управление стават неефективни и нарушават жсизеспособността й”. На тази основа, за оцеляването в условия на криза, връщането към нормалното функциониране на 
системата и по-нататъшното й развитие, е нужна промяна в управлението и в организацията като цяло.

Паралелно с това, кризисните ситуации в организациите трябва да бъдат разглеждани не като концентрация на неблагополучни събития, а като явление, присъщо на пазарната икономика и организационното развитие. Изхождайки от това, управлението на организацията е длъжно да работи в посока към подготовка и предотвратяване на потенциална криза.

За да си изясним кризата като процес, считаме за необходимо да се проследи причинно-следствената верига на всяка организационна криза, а именно (фиг. 1):

\section{причини - симптоми - фактори - протичане на кризата (стадии) -последствия}

Изясняването на всички елементи, звена и връзки в нея ще помогне за процеса на нейното управление.

Преди да изясним разновидностите на отделните елементи в посочената верига, е необходимо да разграничим и точно да дефинираме понятията, свързани с нея.

Причините за кризата са събития или явления, в резултат на които се появяват симптомите и факторите на кризата.

Симптомите на кризата са определени външни проявления, събития или промени в показатели, отразяващи тенденциите за функционирането и развитието на организацията. Те не винаги показват истинските причини за кризите.

Факторите на кризата са събития, показващи определено състояние на обекта или установена тенденция, свидетелстваща за настъпваща криза.

Например, неквалифицираният персонал (причината) може да доведе до делови конфликти (симптоми) и тогава ще се развият факторите на криза като снижаване на качеството, нарушаване на дисциплината и отлив на потребители (Ivasenko, Nikonova, \& Karkavin, 2011).

Cтадиите на кризата показват последователността на възможните етапи, през които организацията преминава при възникването, развитието и преодоляването/непреодоляването на кризата.

Последствията от кризата показват резултатите от финалната фаза в развитието на кризата.

Мащабът на проявление на кризите показва обхвата им. Той може да бъде локален или системен в зависимост от проявлението му.

Преди да изясним разновидностите на отделните елементи в посочената верига, е необходимо да разграничим и точно да дефинираме понятията, свързани с нея.

Причините за кризата са събития или явления, в резултат на които се появяват симптомите и факторите на кризата.

Симптомите на кризата са определени външни проявления, събития или промени в показатели, отразяващи тенденциите за функционирането и развитието на организацията. Те не винаги показват истинските причини за кризите.

Факторите на кризата са събития, показващи определено състояние на обекта или установена тенденция, свидетелстваща за настъпваща криза.

Например, неквалифицираният персонал (причината) може да доведе до делови конфликти (симптоми) и тогава ще се развият факторите на криза като снижаване на качеството, нарушаване на дисциплината и отлив на потребители (Ivasenko, Nikonova, \& Karkavin, 2011). Друг съществен пример е липсата на иновации, която задължително води до организационни кризи (Ivanova, 2019). 


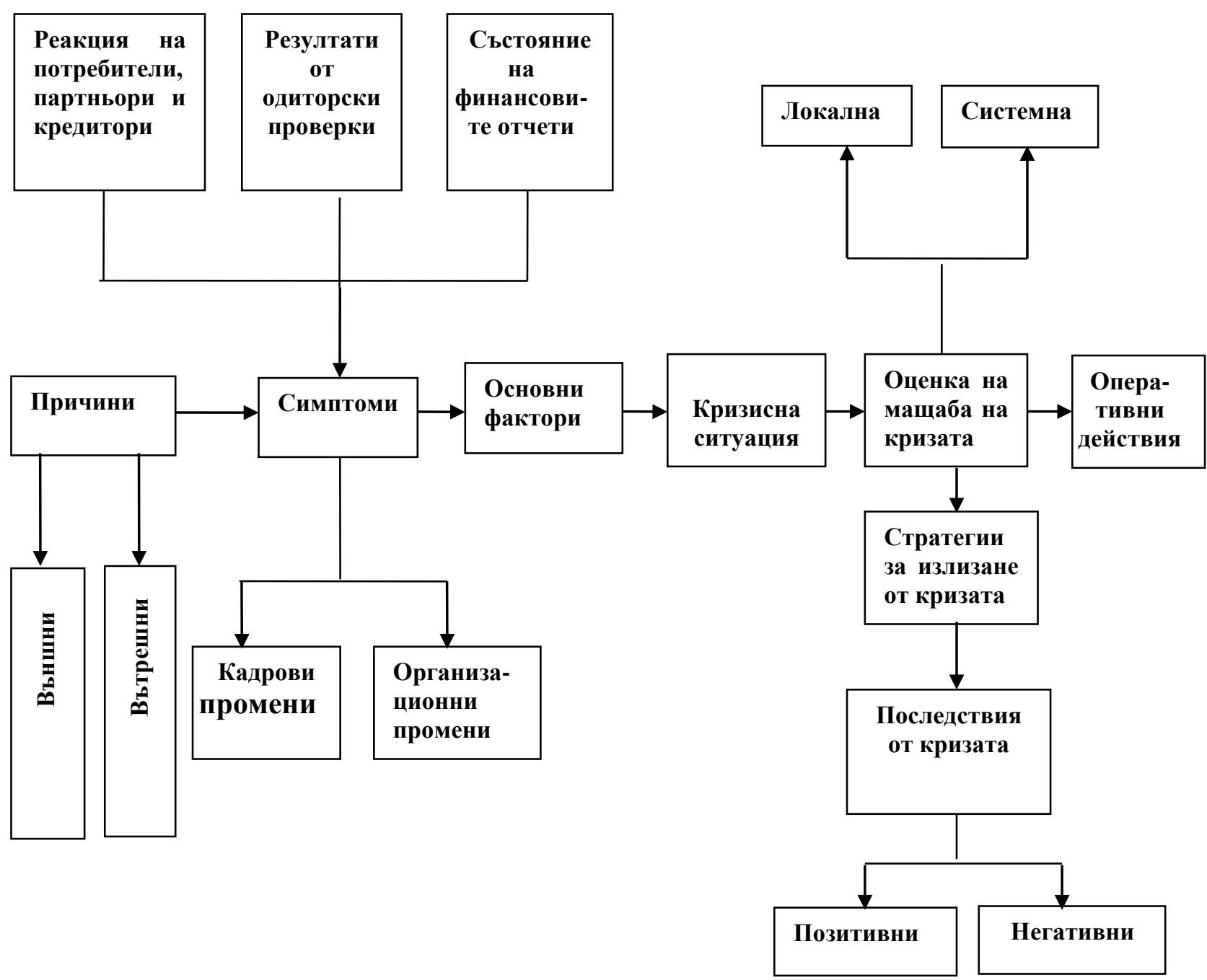

Фигура 1. Причинно-следствена верига на кризисния процес

Стадиите на кризата показват последователността на възможните етапи, през които организацията преминава при възникването, развитието и преодоляването/непреодоляването на кризата.

Последствията от кризата показват резултатите от финалната фаза в развитието на кризата.

Мащабът на проявление на кризите показва обхвата им. Той може да бъде локален или системен в зависимост от проявлението му.

\section{2. Причини за организационните кризи}

Причините за появата на организационни кризи Miller и Mintzberg (1974) в началото на 80те години на XX век откриват в допуснати различни грешки в дейността на организациите:

- те може да са дали твърде голяма власт на топ мениджърите;

- да разчитат прекалено силно на формални процедури, формализирани комуникации и стандартизирани процедури;

- да чувстват неоправдано самодоволство;

- строго да филтрират представите си за средата;

- да имат необичайно нереални убеждения;

- да инициират необмислени експерименти. 
Starbuck, Greve и Hedberg (1978) посочват също, че кризите се случват, защото организации правят грешки и тези грешки могат да се дължат на определени организационни характеристики. Те посочват примера с FACIT като компания, която иска да остане в „остарели” пазари и тази стратегия е подкрепена от топ мениджърите през протестите на мениджърите на по-ниски нива.

Изводът е, че в първите публикации в областта на кризите учените виждат основните причини за организационните кризи в грешките на мениджмънта, която теза не се потвърждава винаги в практиката. Проблемите от недоброто управление водят до кризи, но не са единствените причини за кризите, което се доказва в по-късните публикации на учените в областта.

Разсъжденията на Shrivastava и Mitroff (1987) в едно от първите им изследвания са в посока на това, че кризите са причинени от едновременното взаимодействие на „неизправности” вътре в организациите и проблеми с тяхната среда. На практика те първи извеждат основните източници на причините за възникването на кризите - нарушените (проблемни) взаимоотношения и взаимовръзки между факторите в средата - вътрешна и външна.

В публикацията си тези учени посочват, че неуспехите на организациите във вътрешната среда възникнат в три основни области: технологиите (както в продуктите/услугите, така и в технологичния процес), организационните фактори, и от човешките фактори, като дават следните по-детайлни пояснения:

„Технологическите провали включват проблеми в проектирането, оборудването, консумативите, експлоатацията, безопасността, поддръжката/ремонта и процедурите.

Организационните неуспехи включват: структурни пропуски, които водят до недоразумения; лоши стратегически планове и функционални области и политики, които отделят незначително внимание към безопасността, сигурността и културата; фактори, които изкривяват тълкуването на сигнали за опасност и разработване на технологични системи, които са по-малко надеждни (Perrow, 1984).

Човешките провали, както посочват Р. Shrivastava и I. Mitroff (1987), са под формата на операционни и грешки в управленските решения, които правят технологичните системи по-податливи на злополуки. Посочените вътрешни неуспехи взаимодействат с тези от външната среда, конвертират дребните инциденти в големи събития и сериозните инциденти в катастрофи. Тези пропуски включват: междуорганизационните недоразумения (или липсата на комуникация); посредствени инфраструктурни съоръжения (електричество, водоснабдяване и канализация, транспорт, комуникационни системи) за подпомагане на опасни технологии; недостатъчни регулиращи и контролни разпоредби, които да следят за рисковете в общността; липсата на информация сред членовете на обществото за опасностите, на които са изложени, както и аварийните процедури за работа с тях.“

Потвърждение на тази теза виждаме и в някои концепции и модели, които посочват като една от причините за кризата емоционалната интелигентност на ръководството като водеща в управлението на кризите. В специализираната литература има разработена научна теория (D. Goleman, W. Payne и др.) в тази област, свързана с кризисните ситуации. Според нея, емоционалната интелигентност може да бъде определена като „съзнателно управление на собствените си емоции (D. Goleman, 1995), включващо „възприемане на емоции, улесняване на мисълта с тях, разбирането и регулирането им“ (Mayer, Salovey \& Caruso, 2000). Според Goleman (1995) съществуват пет елемента, които са в основата на модела на емоционалната интелигентност: самосъзнание, мотивация, саморегулиране, съпричастност и опит в отношенията. Изследванията на учените в областта показват, че и организационната ефективност и производителност зависят твърде много от емоционалната интелигентност. Това води до заключението, че тя е и в основата на много грешки на мениджърите, водещи до организационни кризи. 
Не е малка и ролята на техническата интелигентност на ръководството в условията на кризи, особено в някои организации, където се изисква и компетентност в областта на техниката и технологиите. Много малко са учените, които обръщат внимание на тези причини в изследванията си на кризисните процеси.

Mayer (1992) прави различна класификация на причините за организационните кризи, като я свързва със системния подход: конюнктурни - в зависимост от обстоятелствата и структурни, създадени от нарушаването на равновесието в структурните елементи на системата. Тази класификация той прави на базата на системния подход, но не изчерпва цялата съвкупност от причини.

Малко по-късно Thompson и Strickland III (1995), на основата на свои изследвания върху вече минали кризисни ситуации, извеждат най-разпространените причини за тях, като силно ги детайлизират, без да ги класифицират:

- значителен размер на дълга;

- преоценка на перспективите за ръст на продажбите;

- игнориране отрицателното въздействие върху печалбата, в резултат на агресивен опит да се „купи” пазарния дял за сметка на значително снижение на цените;

- високо ниво на постоянната издръжка от неспособността рационално да се използват производствените мощности;

- технологичен пробив в дългосрочен период от време;

- голям размер за изследвания и разработки (големи вложения) за укрепване на конкурентната позиция и рентабилността, и неуспех в разработването на нови ефективни продукти или услуги;

- честа смяна на стратегиите, тъй като предишните не работят;

- отстьпка от конкурентните предимства на по-подходящите от конкурентите.

Те прилагат стратегически подход в техните изводи, разглеждайки кризата като резултат от стратегически действия или бездействие, но отчитайки предимно промените във вътрешната среда.

Други учени, анализирайки причините за организационните кризи, ги свързват с тези на фалита - Argenti (1976), Preble (1997), Shrivastava et al. (1998), Ren (2000), Rosenblatt (2002) и др.

В по-нови публикации Hamilton и Micklethwait (2006) твърдят, че основните причини за кризите могат да бъдат групирани в шест категории:

(1) лоши стратегически решения;

(2) свръхбързо разрастване и необмислени придобивания (покупки);

(3) господстващи главни изпьлнителни директори;

(4) алчност, надменност и желание за власт;

(5) недостатъчен вътрешен контрол на всички нива от горе надолу;

(6) както и неуспешни или неефективни Бордове.

Тази класификация извежда основно вътрешни причини и отново потвърждава тезата на други посочени вече учени за грешки в мениджмънта.

Както А. Thompson и A. Strickland III (1995), така и Hamilton и Micklethwait (2006) търсят причините за кризите във вътрешната среда, като последните я виждат само във висшия мениджмънт. Ако тяхната теза бе правилна, то кризите щяха да се преодоляват много по-бързо със смяна на ръководството или други организационни решения. За съжаление, промените във външната среда, върху която организацията не може да има пряко въздействие и контрол, също са източник на причините за кризисните явления в организациите. Това е характерно особено в държави, където има честа смяна на политиката - напр. в регулационните механизми. Не бива да се забравя, че обикновено в държави със 
силно развита пазарна икономика учените са на мнение, че единствено висшият мениджмънт е виновен за кризите. Причината е, че там той е независим от политическите сили и влияние така, както е в новодемократичните държави и в развиващите се страни.

Една често срещана причина за организационните кризи е противоречието между интереса на собствениците на организацията и мениджмънта, защитаващ интересите й. Намесата на политически партии в управлението, особено на публични организации не е изключение.

На основата на тези разсъждения може да се направи извода, че причините за възникналите кризисни ситуации често се свързват с интересите и влиянието на стейкхолдерите, особено на външните.

Не бива да се пропускат и несъвършенствата в законодателството, честата му смяна, възможностите за заобикалянето му от някои организации и т.н., което също води до организационна криза. Тези причини са често наблюдавани в публичния сектор и в някои други - строителната индустрия, туризма, агробизнеса и др.

За разлика от кризите, предизвикани от външната среда, голяма част от останалите са предизвикани от човешки грешки, както твърдят доста от учените изследователи в областта. Задълбочавайки своите изследвания в тази насока Mitroff \& Silvers (2009) ги класифицират като тип 3 (неволни) и тип 4 (умишлени) грешки. Тази класификация е важна от гледна точка на мениджмънта при търсене на причините и съответно отговорностите и реакцията при кризисни ситуации.

В този аспект, една интересна, задълбочена и доста точна картина на взаимовръзките на причините за кризите дават руските учени (Ivasenko, Nikonova, \& Karkavin, 2011). Те ги свързват с източника на възникването на кризите, събитията или явленията, вследствие на които те са настьпили.

Външните причини са свързани с тенденциите и стратегиите на макроикономическото развитие или даже развитието на световната икономика, конкуренцията, политическата ситуация в страната (разделени са по факторите на PEST анализа - бел.авт.).

Вътрешните причини имат за източник рисковани стратегии на маркетинга на организацията, вътрешните конфликти, недостатъците в организацията на производство, несъвършенствата на управлението, в икономическата стратегия, иновационната и инвестиционната политики, остарели технологии и много други. Руските учени ги разделят на три по-големи групи: управленски, производствени и пазарни.

Kukukina и Astrakhantseva (2004) ги класифицират по същия начин, но представяйки ги в доста по-опростена схема (фиг.2).

За определяне на причините за кризата в аналитичните си оценки Ivasenko, Nikonova, \& Karkavin (2011) предлагат да се използват следните методи за анализ:

- Исторически - като начин да се търсят „корените на всички беди” с проучване на динамиката на изменение на основните показатели на дейността на организацията в различните периоди. Именно този анализ ще позволи да се установи този момент, когато за първи път са възникнали негативни явления и/или фактори, които ги обуславят. След „преломния момент” в безоблачния живот на организацията, трябва да се изясни, какво необичайно се е случило в нея.

- Структурен анализ. Крайният финансов резултат е някаква сума от финансовите резултати от различни видове дейности на различните звена в структурата на организацията. Това налага изясняването на структурните елементи, формиращи финансовия резултат и кои от тях са се оказали под негативно въздействие.

- Класификация на факторите и причините, довели до кризата. 


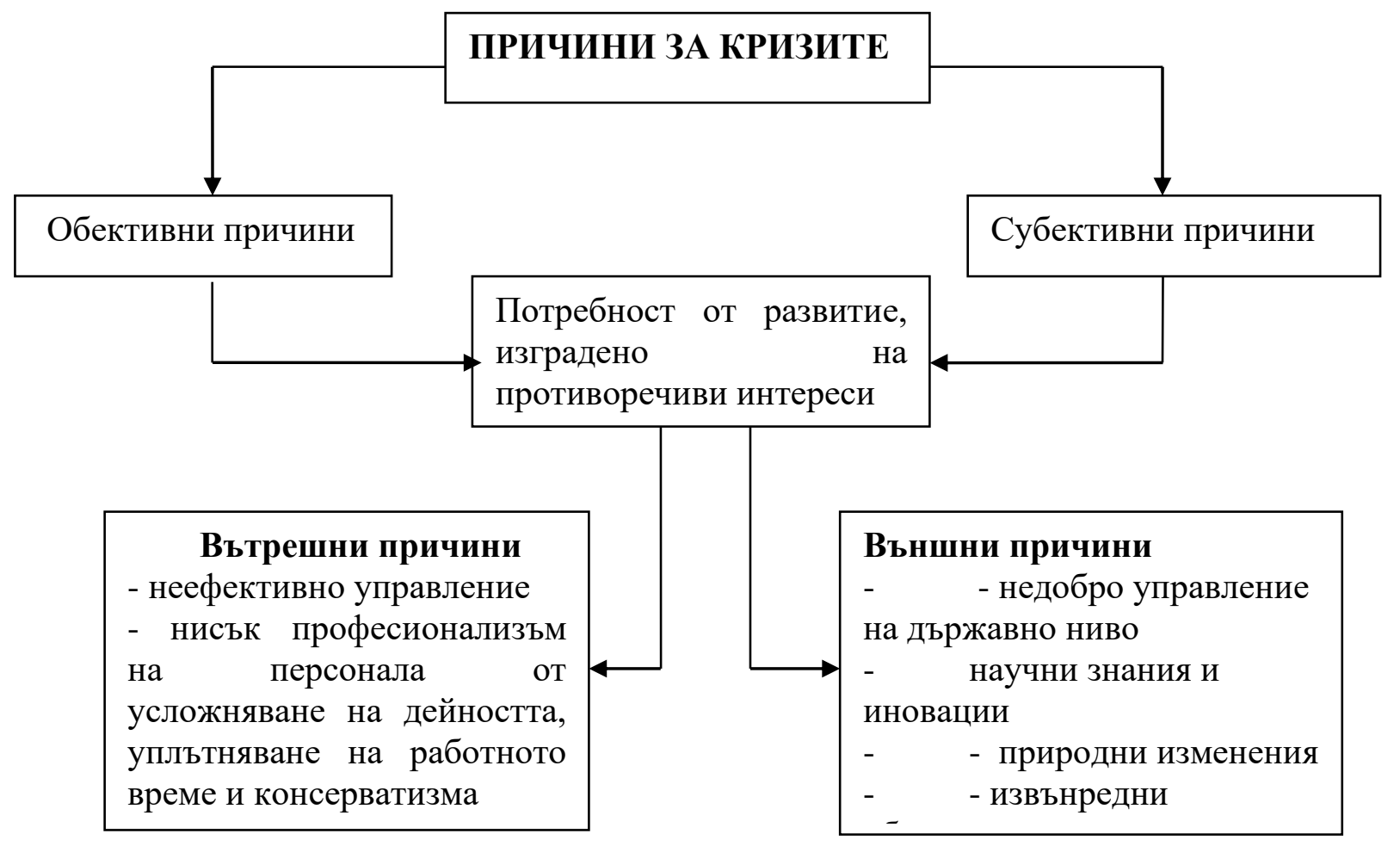

Източник: Kukukina, I.G., Astrakhantseva, I.A. (2004) Uchet $i$ analiz bankrotstv. Moskva: Finansi $i$ statistika, c.11.

Фигура 2. Причини за възникване на кризите в организациите

Тези методи безспорно са важни за изясняване на кризите в организациите, но бихме добавили към тях и другите, включени традиционно в един стратегически анализ - PEST, SWOT, Портъровия анализ на конкурентната среда (при наличието на конкуренция в бранша или бизнеса), балансираността на ресурсите, веригата на стойността и т.н. Но приоритет в посочените методи на анализ и оценка трябва да имат тези, които дават много по-бързи оценки, тъй като времето за реакция е кратко.

Подкрепяме становището на Kukukina и Astrakhantseva (2004), които обрьщат внимание, че при анализа на кризата с цел да се търсят нейните причини трябва да се имат предвид обхвата на социално-икономическата система, структурата на тези система и средата, в която функционира.

Като обобщение за причините, които водят до организационни кризи, можем да посочим следните:

Първо, съществува дискусия по отношение на причините за възникване на кризи. Източниците на организационните кризисни явления обикновено се търсят както в организацията, така и в нейната външна среда, взаимоотношенията и връзките между отделните елементи в цялостната система. Основните кризисни ситуации се дължат на влияние на различни стейкхолдери върху дейността на организацията.

Bторо, основните причини за кризите са взаимоотношенията между индивидите, структурните звена и нивата на мениджмънт вътре в организацията. Това може да са конфликти между мениджърите, недоволство от страна на персонала по отношение на някакви управленски решения - размер на работни заплати, условия на труд, неритмични плащания, съкращения, новоназначения и др. До кризисни ситуации може да доведат и 
структурни промени, вътрешно преразпределение и обединение на дейности, бюрокрация, безотговорност, липса на контрол, хаос, липсата на координация между звената и др. Особено голям дял имат финансовите проблеми на организацията, които са плод на управленски грешки. А те най-много засягат интересите на стейкхолдерите и водят до кризи.

Трето, взаимоотношенията с външната среда са от първостепенно значение при появата на организационни кризи. При промени в нея, засягащи организацията, мениджмънтът трябва да реагира много бързо, за да не се стигне до кризисни ситуации. Вероятно това е основният аргумент за становището на много учени, че организационните кризи се дължат на мениджърски грешки.

Причините за кризите са източник на много процеси, свързани помежду си, които могат да доведат до сериозни сътресения организацията, а дори и до фалит. За да бъдат те предотвратени, ръководството трябва задължително да реагира на ранните сигнали за кризисни ситуации. Необходимо е да се изследват постоянно факторите на средата, които влияят върху организацията. Целта е навреме да се проучат промените, за да може организацията да се подготви за тях.

\section{3. Фактори, оказващи влияние върху предизвикването на организационни кризи}

За по-детайлното изучаване на причините за кризите е необходимо да изследваме факторите, които ги предизвикват. Mellahi и Wilkinson (2004) посочват, че кризата се влияе от:

- фактори на средата (технологични, регулаторни и икономически промени);

- екологични фактори (плътност, размер, възраст, жизнен цикъл на индустрията);

- организационни фактори (управленски мандат, хомогенност и наследство, резултати в миналото);

- психологически фактори (управленски възприятия).

Считаме, че тази класификация е до известна степен добра, но не е изчерпателна, в някои отношения неточна и буди много въпроси и дискусии - напр. за мястото на екологичните фактори, както и на психологическите.

Съществуват и други по-категорични класификации (Kozhevnikov (2005), Korotkov (2006), които в зависимост от участието на управляващите в тях можем да ги разделим на:

- Обективни - свързани с потребността от модернизация и преструктуриране и определящи условията на стопанисване: икономическа нестабилност; несъвършенство на финансовите, кредитно-паричните, данъчната и митническата системи, нормативно-правната и законодателната база в икономиката; грешки в организацията на приватизацията, инфлационните процеси, ниската платежоспособност на населението; международната конкуренция.

- Субективни - управленски, получени вследствие на грешки и недостатъци в управлението или вътрешни фактори на дейността на организацията: намаляване на обема на продажбите поради ниско ефективен маркетинг; намаляване обема на производство, качеството и цената на продуктите (услугите); неоправдано високи разходи и дълъг цикъл на производство, произтичащи от незначителното ниво на технологично оборудване; ниска рентабилност; взаимни задължения; небалансиран икономически механизъм на възпроизводство на капитала; консерватизъм в управлението.

Посочените фактори от руските учени са свързани само с вътрешната среда на организацията. Но както тя може да влияе на развитието на организацията, така и външната среда оказва своето въздействие. Това налага систематизацията на възникването им, т.е. да се разграничат на външни и вътрешни. Външните зависят от общите цикли на икономиката, а вътрешните - от собствените цикли и кризи на развитие на организацията (Kukukina и 
Astrakhantseva, 2004; Orekhov, Baldin и Gaponenko , 2006 и др.), а именно:

А. Външни - несъвършенства в управлението на макро, мезо и микро ниво, промени в законодателството, иновации (нови научни знания, развитие на НТП), природни изменения (напр. влошена екологична обстановка), непредвидими обстоятелства, промяна в пазарните условия, натиск от конкуренцията, държавно регулиране, законодателни промени, промяна в политическата ситуация и др.

Б. Вътрешни - неефективен мениджмънт на организацията поради непрофесионализма му, усложняване на дейността вследствие на разширяването й и консерватизма на мениджърите, саботиране от страна на персонала и неформалните лидери.

Някои руски учени (Kukukina и Astrakhantseva, 2004) класифицират външните и вътрешните фактори на различни типове:

А. Външни - общоикономически, държавни, пазарни и др.

Б. Вътрешни - операционни (производствени и управленски), финансови, инвестиционни, други.

А Андреева (2011) в свое изследване детайлизира вътрешните и външните фактори на такива с позитивно и с негативно действие (D. Andreeva in: Iliev, Y. (red.) (2011).

Като обобщение на изследването на специализираната литература в областта бихме могли да посочим:

Първо, дълбоките причини за разразяващата се организационна криза се крият в много различни фактори. Успехите и неудачите от дейността на организацията следва да се разглеждат като взаимодействие на редица фактори: външни - върху тях организацията не може да влияе или влиянието може да бъде слабо, и вътрешни - като правило те зависят от организацията на работа.

Bторо, външните фактори за възникване на кризата в организацията можем да разделим на:

А. Социално-икономически фактори (ръст на инфлацията, нестабилност, данъчна система, регулиращо законодателство, снижаване на нивото на реалните доходи на населението).

Б. Пазарни фактори (снижение на емкостта на вътрешния пазар, усилване на монополизма в него).

В. Други външни фактори (политическа нестабилност, стихийни бедствия, влошена криминогенна ситуация).

Трето, вътрешните фактори за възникването на кризата можем да сведем до следните:

А. Управленски (високо ниво на търговския риск, недостатъчно знание за конюнктурата на пазара, неефективен финансов мениджмънт, отсъствие на гъвкавост в управлението, некачествена система на счетоводен отчет и отчетност).

Б. Производствени (остарели и износени ДМА, ниска производителност на труда, кадрови проблеми, пренебрежение към обектите от социалната сфера).

Четвърто, освен тези класификации, съществуват и други, като по-известно е разграничението им на:

- случайни - такива, които не могат да бъдат предвидени или прогнозирани;

- закономерни - произтичащи от цикличността на икономическите процеси, жизнения цикъл и др.

\section{Заключение}

Изследването на някои важни звена от причинно-следствената връзка в процеса на организационните кризи показва, че особено внимание е необходимо да се обърне на 
причините, водещи до възникването на организационни кризи и факторите, влияещи върху тези процеси. Това ще помогне за превенцията и предотвратяването на кризисни ситуации и/или намаляването на негативните последици от тях.

Независимо от произхода на факторите, които влияят върху кризите, не бива да се отчитат непременно като причини за кризисните събития, върху които мениджмънтът не може да оказва влияние. Дори и при случайните, както и при закономерните фактори, ръководството може да прогнозира тяхното влияние и да оказва въздействие. Дори и влиянието на природните бедствия и умишлените саботажи могат да бъдат ограничени, като предварително се разработят и внедрят съответните системи - напр. за управление на риска, за ранно предупреждение и др.

\section{References}

1. Argenti, J. (1976) Corporate Collapse: Causes and Symptoms. London: Mc Grey Hill.

2. Golemann, D. (1995) Emotional intelligence. Bantam Books.

3. Hamilton, S., Micklethwait, A. (2006) Greed and corporate failure. New York: Palgrave Macmillan.

4. Iliev, Y. (red.) i dr. (2011) Antikrizisno upravlenie na industrialnite firmi. Sofiya: Avangard Prima.

5. Ivanova, R. (2019) Upravlenski aspekti na otvorenite inovatsii i sreda za prilozhenie $\mathrm{v}$ Balgariya. Varna: Nauka i ikonomika. Kniga 57.

6. Ivasenko, A.G., Nikonova, Ya.I. and Karkavin, M.V. (2011) Antikrizisnoe upravlenie. (2-oe izd.), Moskva: KNORUS.

7. Korotkov, E. M. (2006) Antikrizisnoye upravleniye. M.: INFRA - M.

8. Kozhevnikov, N.N. (2005) Osnovy antikrizisnogo upravleniya predpriyatiyami. Moskva: Akademiya.

9. Kukukina, I.G., Astrakhantseva, I.A. (2004) Uchet $i$ analiz bankrotstv. Moskva: Finansi i statistika.

10. Mayer, P. (2002) Organisation in crise. Une perspective clinique et analytique. Gerer et Comprendre, 28, pp.84-94.

11. Mayer, J. D., Salovey, P. and Caruso, D. R. (2000) Models of emotional intelligence. In: R. J. Sternberg (ed.), Handbook of Intelligence (pp. 396-420). Cambridge: Cambridge University Press.

12. Mellahi, K., Wilkinson, A. (2004) Organizational Failure: A Critique of Recent Research and a Proposed Integrative Framework. International Journal of Management Reviews, 5-6 (1), pp. 21-41.

13. Miller, D., Mintzberg, H. (1974) Strategy Formulation in Context: Some Tentative Models. Working Paper, McGill University.

14. Mitroff, I., Anagnos, G. (2001) Managing Crises before They Happen: What Every Execute and Manager Needs to Know about Crisis Management. N.Y.: AMACOM, American Management Association.

15. Mitroff, I., Silvers, A. (2009) Dirty Rotten Strategies: How We Trick Ourselves and Others into Solving the Wrong Problems Precisely (High Reliability and Crisis Management). Stanford: Stanford University Press.

16. Orekhov, V.I., Baldin, K.V., Gaponenko, N.P. (2006) Antikrizisnoye upravleniye. Moskva: INFRA-M.

17. Perrow, Ch. (1984) Normal Accidents: Living with High Risk Technologies. N.Y.: Basic Books.

18. Preble, J. F. (1997) Integrating the Crisis Management Perspective with the Strategic Management Process. Journal of Management Studies, 34 (5), pp.769-791. 
19. Ren, C. (2000) Understanding And Managing The Dynamics Of Linked Crisis Events. Disaster Prevention and Management, 9 (1), pp. 12-17.

20. Rosenblatt, Z. (2002) Effects of Crisis - Triggered Demographic Depletion on Organizational Change. Journal of Contingencies and Crisis Management, 10, pp. 26-38.

21. Shrivastava, P., Mitroff, I. I. (1987) Strategic Management of Corporate Crises. Columbia Journal of World Business, Spring, pp.5-11.

22. Shrivastava, P., Mitroff, I. I., Miller, D., Miglani, A. (1988) Understanding Industrial Crises. Journal of Management Studies, 25 (4), pp.285-303.

23. Starbuck, W., Greve, A., Hedberg, Bo L.T. (1978) Responding to Crisis. Journal of Business Administration, 9 (2), pp.111-137.

24. Shrivastava, P., Mitroff, I. I. (1987) Strategic Management of Corporate Crises. Columbia Journal of World Business, Spring, pp.5-11.

25. Thompson, A., A. Strickland III. (1995) Strategic Management. Crafting \& Implementing Strategy. (6-th ed.) IRWIN. 